\title{
Growing up with parental substance use disorder: The struggle with complex emotions, regulation of contact and lack of professional support
}

Turid Wangensteen ${ }^{a, b}$, Jørgen Gustav Bramness ${ }^{c, d}$, Astrid Halsa ${ }^{b}$
a) Tyrili Foundation, Lillehammer, Norway
b) Inland Norway University of Applied Sciences, Lillehammer, Norway
c) Norwegian National Advisory Unit on Concurrent Substance Abuse and Mental Health Disorders, Inland Hospital Trust, Hamar, Norway
d) Institute of clinical Medicine, University of Troms $\varnothing /$ University of the Arctic, Troms $\varnothing$, Norway

\section{Corresponding author:}

Turid Wangensteen

Tyrili Foundation

Løkkegata 11

Lillehammer 2615

Norway

E-mail: tuwa@tyrili.no

Telephone: +4790864026

\begin{abstract}
The aim of the study was to explore young peoples' perceptions and reflections about growing up with parents who have substance use disorder (SUD). In qualitative interviews with 12 young people (aged $13-26$ ) and in an interpretative phenomenological analysis (IPA), we investigated their experiences of everyday life, of the relationships with the parents with SUD, and of conversations about this, both retrospectively and at the present. The findings indicated that the relationships with the parents largely occupied the informants, even when they lived separately from the parent and were protected from the daily exposure of substance use. The informants described their mixed and contradictory emotions towards their parents and the struggle to determine regulation and type of contact. They asked for professional support in order to help them cope with this.
\end{abstract}


Sociocultural discourses concerning family life and substance use were discussed in an attempt to understand the findings. The findings of the study suggest that children and young people should be offered sufficient professional support in order to cope with their mixed and contradictory emotions and to determine the regularity and type of contact with the parents.

Key words: substance use disorder, drug abuse, parental SUD, child protection, childrenparents relationship

\section{Introduction}

A significant number of children grow up with parents who have a substance use disorder (SUD) (Reupert et al., 2012; Velleman \& Templeton, 2016). Persons with SUD use alcohol and/or legal or illicit drugs to the extent that they lack the control or ability to regulate their substance use. They continue to use despite negative consequences in physical and mental health, family relationships and social function. Parental SUD is often associated with shame and fear of intervention by child protection services (Backett-Milburn et al., 2008; Werner \& Malterud, 2016a; Wilson et al., 2012). Therefore, many families try to conceal their problems and avoid contact with social and health care services.

The long-term consequences for children who grow up with parents with SUD are serious. They are at risk of developing emotional and mental health problems, substance use problems, problems in school, and problems with social relations (Dube et al., 2001; Raitasalo \& Holmila, 2017; Velleman \& Templeton, 2016). A home environment affected by parental SUD may also include violence and sexual abuse (Dube et al., 2001; Velleman et al., 2008). Many children feel lonely, experience stigma, lack trust in their parents and assume much responsibility at home, such as caring for parents and siblings (Kallander et al., 2017; Moore et al., 2011). Interviews with adult children of alcohol-dependent parents emphasize 
the lack of professional attention they receive during childhood (Templeton et al., 2011; Werner \& Malterud, 2016c). Research on children growing up with parents with SUD focuses on children's grief and anger because of the parents' failure to fulfil expected parenthood obligations, such as watching football games, joining school events, remembering birthdays and keeping promises (Holmila et al., 2011; Wilson et al., 2012). Despite this, children still consider family as important and maintain idealised expectations of the parents' care, even when they experience the opposite (Backett-Milburn et al., 2008).

Most of the research focuses on children's emotional challenges and disrupted daily life when parents and children live together. However, most commonly, the parent with SUD has to move out of the home. If both the parents have SUD, then this may cause children to be placed into foster care. Both measures ensure that children are being protected from daily exposure to parents' substance use, but the children also experience a loss of daily contact.

The literature emphasizes that continued contact between children in foster homes and their parents is of importance, especially in order to maintain the parent-child relationship. Regular contact between children and parents is considered positive for children's wellbeing and mental health, but it may also be complicated (McWey et al., 2010; McWey \& Mullis, 2004). Parental SUD often brings along lack of regularity and stability in contact with the children, due to the substance use and periods in treatment or prison. These children are often in long-term foster care and become emotionally attached to their foster parents. Some experience loyalty conflicts between birth and foster parents (Baker et al., 2013). Children have, despite the complexity of having two sets of parents, a right to maintain contact with their biological parents, as pointed out in the United Nation's Convention on the Rights of the Child (United Nations, 1989). Research points out that children should not be pushed into contact with biological parents when they experience it as stressful and uncomfortable (Holmila et al., 2011; Kiraly \& Humphreys, 2013; Sinclair et al., 2001). Most often, foster children want some sort of contact with their biological parents and other family members as long as they have influence over the frequency of contact (Sinclair et al., 
2001). Research suggests that the content of the contact is more important than frequency, and visits should take place in home-like environments, be emotionally safe, informal and should include activities (Haight et al., 2003; Kiraly \& Humphreys, 2013; McWey et al., 2010). There is a need for professional support and supervision of children, parents and foster parents in order to improve the quality of the contact (Kiraly \& Humphreys, 2016).

Sociological and psychological literature has focused on how family relationships are crucial in people's lives, more so with children. When children talk about their parents they often communicate about themselves (Smart, 2007). Family represents relationships of love and commitment, but may also include secrets and betrayal (Smart, 2007; Wiig et al., 2014). Hence, an understanding of how children construct meaning and the emotional significance of these parent/child relationships can help us to support children growing up in such situations (Reupert et al., 2012; Smart, 2007; Werner \& Malterud, 2016a; Wilson et al., 2012). The aim of the study was to explore young peoples' experiences of growing up with parents with substance use disorder (SUD), in order to understand more about their everyday life, their relationships with their parents, and conversations they had about SUD during childhood and adolescence.

\section{Methods}

Through in-depth interviews with 12 young people, we explored how they experienced their everyday lives, their relationships with their parents with SUD and conversations about this, both retrospectively and at present. The purpose of using this method was to enable the youths to express their experiences, thoughts and feelings in their own words (Heath, 2009; Silverman, 2006). Ethical considerations were taken into account during recruitment, in the interviews and in the analysis and interpretation of the data. The Norwegian Centre for Research Data and Regional Committees for Medical and Health Research Ethics approved the study. 


\section{Informants}

The informants were recruited via professionals and family members. They received written information and a consent form to sign ahead of the interview. For those under the age of 18 , a parent also signed the consent form.

The inclusion criteria for informants were as follows. First, young people (youths and young adults) with experience of parental SUD. At least one parent was in treatment or in active use of substances at the time of interview. Second, the informants did not live together with the substance-dependent parent at the time of the interview and during parts of their childhood. Third, they were not themselves receiving treatment due to mental illness or harmful substance use.

The 12 informants, three male and nine female, were 13 to 26 years of age. The younger informants $(13-19)$ and the older ones $(20-26)$ responded to some of the questions differently, which has been included under Findings. The cut-off at 19 years was chosen because those older than 19 all lived by themselves. That made them more independent than the younger ones who lived together with parents or foster parents. The older informants did largely look back on their childhood in the interview, the younger were more concerned about the present situation.

Only two of the informants' 24 parents had never had any SUD. Most of the parents had problems with use of illegal substances and two of the parents had mainly alcohol problems. The informants had periods where they lived together with parents with SUD, but they also had several years living in foster homes or with only one sober parent. At the time of the interview, six of the 22 parents were in treatment, eight were in active use of substances, four where sober, and three were dead. Four of the informants lived with a sober parent, one lived in a foster home, and seven had their own housing. 


\section{Interviews}

The interviews took place at the informants' homes, at the researcher's office or in cafes during the period between October 2014 and January 2017. Two of the authors (TW and AH) conducted seven and five of the interviews each, respectively, as parts of a larger study with several researchers. The interviews mainly followed the same approach, starting with an open question where the informants were asked to tell the authors about themselves and their family, their every-day life, and about their experiences of growing up with parents with SUD. The following questions went deeper into the informants' stories depending on what they talked about (Heath, 2009). Each interview lasted between one and one-and-ahalf hours. The interviews were recorded and transcribed by the interviewers (TW and $A H$ ).

\section{Analysis}

To analyse the data-material, interpretative phenomenological analysis (IPA) was used (Smith et al., 2009). This included both interviewers reading the transcribed interviews several times looking for the informants' experiences, emotions and thoughts. Second, both researchers investigated the informants' interpretations of their own stories and special events and finally focused on the researchers' interpretations of informants' interpretations. Both the common features of the informants' stories and the unique stories and exceptions have been of interest. The transcribed interviews were systemized in the NVivo software, which is designed for coding and analysing qualitative data, and the following themes emerged: 1) the informants' relationship to their parents, 2) the informants' dialogs with others about their childhood and their parents' substance use and 3) emotions and thoughts related to childhood. During a second reading, we used these themes to further explore and understand the informants' perceptions and reflections. The next step was to be more aware of the details in their stories. During this process, three new and narrower themes emerged: 1) mixed and contradictory emotions towards the parents, 2) negotiations of closeness and distance in the relationship and 3) lack of professional support. These themes are reflected in the subheadings in the findings. 


\section{Findings}

The informants talked about their relationships with their parents with SUD, their struggle to regulate contact and the lack of professional support both retrospectively and at present. Their stories included both periods where they lived together with their parents with SUD and those periods where they lived separately.

\section{Mixed and contradictory emotions}

The informants were for periods of their childhood preoccupied with thoughts and feelings concerning their parents, even when living apart and sheltered from the substance use. The insecurity that follows a relationship with a parent with SUD was described as very demanding. They had long periods of not knowing where the parents lived and whether they were on drugs. Several of the informants mentioned the fear of overdose and death. One young man expressed it this way:

What is crazy about this is not that she is using drugs, but the fact that everything seems to be so fine when she is in treatment. Then, just a couple of weeks later, it is back to hell again. (...) The only thing in life I am afraid of is that she will die (male, 21).

The emotional ties, the attachment and the longing seemed to be strong despite adverse childhood experiences due to the parental SUD. They wanted to spend some time with the parent. That did, however, sometimes end in challenging situations.

He was on drugs. He was so aggressive when I tried to wake him up. I just wanted us to play PlayStation. He said: "Get the fuck out of here." I got so afraid (male, 13).

All the informants mentioned they had been afraid. This was because the parents behaved differently and strangely when they were on drugs or drunk. One female found her mother unconscious several times during childhood. Others had experiences of domestic violence and loud arguing. The informants told how they, as children, perceived the mood and the atmosphere as tense and insecure. One of the females told about her relationship with a violent and alcohol-dependent father. She described her mixed emotions this way: 
Even though he was like that, violent, to mum... He was such an important person to me. He gave me the security I needed. He was never mean to me. I cannot hate him, I cannot (female, 16).

Several reflected on the theme of anger. They felt that they were expected by nearby adults to be angry with their parent because the parent had betrayed them, let them down and hurt them. Nevertheless, none of them mentioned anger as the most prominent emotion: I can't be angry with my mum. I can feel many things, like disappointment, betrayal, grief, but not anger (female, 25).

All of them did, however, acknowledge the feeling of anger as a relevant and acceptable feeling, even if they found it difficult to be angry themselves.

Those of the informants who understood the substance use as a disease seemed to blame the parents less. They were able to make a distinction between the person and the problem: When I got older, I understood mum's disease better - she did not give me away because she wanted to. She knew I would have a better home with someone else (male, 21).

Another of the informants said this about their understanding of their parents' substance use:

They told me that heroin addiction is a disease, which it actually is. Understanding this made it easier for me to talk to others about it (female, 23).

Almost all the informants talked about their relationship with their parents with disappointment, grief and love:

She tried several times to sober up, but she could not do it. Maybe we, the children, should have been protected earlier. On the other hand - I am happy for the strong ties I have to mum today. (...) She said all the time that she loved us, but when she chose her substance-dependent boyfriend instead of us... I did not talk with her for almost one year. (....) Mum is the best mum ever, when she is sober (female, 22). 
Looking back on their childhood, the older informants referred to the sadness of living separated from the parent. They were, nevertheless, satisfied by being sheltered from the substance use. They described this ambivalence by telling us about their experiences of neglect, betrayal and egocentric parents and about the love of their parents and the desire to sustain contact.

\section{Struggling with closeness and distance}

The informants described their attempts to regulate contact with the parents. Age and living arrangement influenced the ability to determine regularity and type of contact. The younger ones still lived with their parents or foster parents and had less impact on the extent of contact. A few of them explicitly expressed that they did not miss their parent and that they were content with minimal contact.

I do not miss her. She is so strange. She always forgets what I say. I must tell her the same thing over and over again (female, 17).

In particular, the youngest informants clearly stated that they longed to live a normal life without too many interruptions. The older ones confirmed this by looking back on their childhood. One of them grew up in a foster home and she described how her mother disrupted her feelings of normality by showing up at school events. At one point in secondary school, she asked her mother to stay away:

I didn't want mum to come. I was embarrassed, probably shameful. I thought mum was different from the others. She was not on drugs or drunk, but she behaved differently.... And people around noticed (female, 25).

Similarly, some of the other older informants described how they tried to keep physical and emotional distance from their parents during childhood. One wrote angry letters to his mother telling her he would not see her anymore. One escaped the demanding family relationships by joining a student exchange programme in high school, living abroad for a year. Another refused to see her mother for almost a year because she felt betrayed. This avoidance of contact was explained by the insecurity and disappointment of never knowing the parent's condition, whether they were sober or drunk, in treatment, in prison, or with a new partner. 
It's hard to have a relationship with a person who goes through extreme transformations like that - all the time. (...) We had almost no contact for some years (...) Today, we have a close relationship (male, 21).

Looking into the informants' reflections, it seemed that growing up in kinship care (foster homes with grandparents or other family members) made it even more difficult to regulate contact. The parents visited their family more frequently (the children's foster-parents) when they were drunk or on drugs. The family tried to help by offering money, a meal and an opportunity to belong to the family. The children did, on the one hand, appreciate this, but it also made them insecure and limited their ability to protect themselves.

Mum often spent time with my grandparents and me. She was often high, and that was scary, of course. I noticed she was different. She was less attentive. I asked her, Why are you sad, why do you cry? I knew because of that look in her eyes (female, 23).

Despite this struggle, those who grew up in kinship care accentuated that living with their grandparents or other family members was the preferred solution. This made the contact with their parents more regular and under natural conditions. They expressed relief at not being forced to move into a new and unknown family.

Many, especially the older informants, felt sorry for their parents and perceived some sort of obligation to spend time with them. They reflected on how they had to defend their parents when they were younger. They remembered that grandparents, foster parents and even social workers talked about their parents in a patronizing way and were disappointed and angry with them.

I have been alone a lot. The rest of the family sort of gave up on my mum (...). I am tired of her, too, but someone has to defend her (...) I often feel obligated to spend some time with her. She wants to spend a lot of time with me. I do understand her, because she lost a lot of my childhood, and she probably has a bad conscience... and so on (female, 22).

They found themselves in the middle of a conflict between their grandparents or other adults and the parent. Because they felt everybody else had let the parents down, the 
children would stand up for them and spend time with them. The older informants had few memories of social workers or foster-parents who talked to them about the frequency and location of the contact with the parents. Those who had dialogs about this, found it difficult to express their thoughts and feelings because of their mixed emotions towards the parents. Hence, many strived on their own to regulate the contact.

Both the younger and the older informants struggled with the tension of keeping a suitable distance and a desired closeness with the parent that they worried about, loved, felt sorry for and missed. This caused much pain and strain and this struggle followed the older informants as young adults living on their own.

\section{Lack of professional support}

The informants underlined the lack of support in dealing with the emotional struggle and their attempts to regulate the contact, both as children and as young adults. Some of the older informants wanted to talk with their parents about childhood experiences and about their relationship. They were tired of coping with their mixed emotions and with certain events and situations in the past. They longed for confirmation that it was acceptable to have these feelings.

I need to talk with my mum about it, but it is very difficult for her. When I try to tell her how I feel about my childhood, she gets so upset. I feel that if we talk about it and she goes back to the drugs and maybe even dies, then - it'll be my fault (female, 25). The informants described how their parents had a limited ability to talk about the relationship between them and about themselves as parents. The informants wanted the parents to listen to their stories and to approve their emotions and thoughts. They missed professional support in these attempts to talk with their parents.

Some had experiences of receiving useful professional support, arranged by themselves, in their late teens. They got help to cope with the contradictory emotions and with the regulation of contact. They did, however, wish that it had happened earlier.

I was never offered any help when I lived in the foster home. I am sorry about that today. I should have had the opportunity of talking to someone (...) A friend of mine was invited to the treatment centre her mother stayed in. They talked with a family 
therapist, I think. I wish mum and I could have had the same opportunity to talk together (female, 25).

Most of them had never been offered anyone to talk to, apart from family and foster family. Not having any trusted professionals to talk to about the chaotic, confusing and mixed emotions reinforced the informants' feelings of being different and lonely.

When I was 15 I asked for some help, I felt I had needed it for a long time. Nevertheless, I experienced that my foster mother didn't care. She just said: Go and fix it. Like that. It wasn't easy though; I couldn't do it. (...) I have been alone a lot (female, 22).

Others talked about the focus by professionals and family members on the parents and the lack of attention on them, the children. The informants mentioned the SUD as very overwhelming for family members, foster families, and social workers - making it difficult for them to talk to the children.

People talk about the problem, but not of the consequences of the problem. I am one of the consequences of the problem. They keep talking about my mother: "Your mum is on drugs, your mum is off drugs, your mum is in treatment, your mum is in the process..." I do understand it, but we never talked much about me (male, 21).

The informants all stressed the importance of having someone with whom they could share their thoughts and feelings. They wanted support to talk with their parents, and they wanted an interlocutor for themselves. They longed for a trusted adult that was not the parent, foster parent or child protection services. 


\section{Discussion}

Our analysis points out the importance of paying attention to the relationship between children and their parents with SUD, even when they are living apart. The relationship largely occupied the children's thoughts and feelings. The informants stated the need for professional support during childhood and adolescence, in order to sort out the contradictory emotions and the contact with their parents. The findings are discussed within the framework of sociocultural discourses about parenting and substance use.

\section{Family ties are often experienced as demanding}

Children's mixed emotions towards their parents with SUD are well-documented (BackettMilburn et al., 2008; Gullbrå et al., 2016; Werner \& Malterud, 2016a; Wilson et al., 2012). These children often have strong emotional tensions concerning their parents and feel both betrayed and loved at the same time (Backett-Milburn et al., 2008). In these studies, young people express not only love for their parents and notions of moral obligation but also a feeling of betrayal that follows this obligation (Wilson et al., 2012). Separation from parents and other family members causes strong feelings of loss and pain for children in foster homes (O'Connor et al., 2014). Young people underline the importance of contact with members of their biological family, but not necessarily their parents (Kiraly \& Humphreys, 2013). This was underpinned by our study, in which the informants pointed out the important attachment both to the biological parents, to foster parents and to grandparents and other family members.

There are established common apprehensions of what is "normal" in regard to family life and parenting, as well as some moral rules and values, such as always giving children priority (Wilson et al., 2012). In most societies, family is highly valued as the base of identity development, emotional and economic safety, and in the creation of a common history (Smart, 2007). When Western idealized parenthood is so highly valued, dealing with failure might be too challenging for both the parents themselves, the children, family members and professionals (Halsa, 2017; Wilson et al., 2012). Parents, particularly mothers, who breach such expectations often blame themselves and are additionally judged by society. The informants mainly talked about their relationship with their mothers, as they seemed to 
have been more present in the informants' childhood than their fathers. This finding is in line with research on marginalized fathers, which demonstrates that potentially destructive fathers are kept out of children's lives and often made invisible (Söderström \& Skårderud, 2013). Thus, the mothers' reluctance to talk about the children's childhood experiences could be interpreted as a manner of protecting their own dignity as a mother. Listening to the children's accounts might be a confirmation of their shortcoming of cultural standards for what a parent, particularly a mother, should represent for a child.

Biological family and parent-child relationship are considered crucial in peoples' lives (McWey et al., 2010; Wilson et al., 2012). However, these family relationships could also be perceived as "sticky" and difficult to escape (Smart, 2007). These characteristics influence young peoples' perceptions and reflections about themselves and their family life and may help us understand why none of the informants in this study expressed a demand to end the relationship with their mothers. They longed for a "normal" life that was not too interrupted by their parents, and they struggled to keep a certain distance. Nevertheless, they also expressed love for their parents and wanted to spend time with them.

\section{SUD as a choice or a disease}

The demanding childhood experiences that entail having one or both parents with SUD are well-documented in several studies (Dube et al., 2001; Holmila et al., 2011; Raitasalo \& Holmila, 2017; Velleman \& Templeton, 2016). What makes SUD especially challenging is the inexpedient behaviour, which is what other people notice and focus on. Our informants told us about family members, foster parents and social workers who judged their parents for using substances. According to the children, they only saw a person who betrayed their children and who chose drugs rather than the child. These ways of understanding substance use are common among most people - they see the use of substances as voluntary and often connected to weak or morally bad persons (Henden, 2016; Järvinen, 2015). The informants did, to some extent, understand their parents' substance use the same way when they were children. They were disappointed with their parents. They experienced, however, that they had limited possibilities to express these feelings because they felt that somebody 
had to defend the parents. As young adults, many of them seemed increasingly able to separate the problem from the person in more mature ways than the nearby adults (Lundby, 2014; Reupert \& Maybery, 2010). They did explain the parental SUD as a disease. The diagnosis criteria of SUD places the craving for substances over almost everything else. When a person has become addicted, the use of substances is no longer perceived as a voluntary choice (Camí \& Farré, 2003; Sellman, 2010). The informants who acquired such knowledge as teenagers or young adults said that it helped them understand their adverse childhood experiences and to comfort themselves. This appeared to be the case for one of the informants who pointed out that his mother did not give him away to foster parents because she wanted to, but because of the disease.

The problems with SUD are most often not constant but vary over time, and a period of abstinence is often followed by relapse (Daley \& Douaihy, 2015; Nordfjærn, 2011). That period provides children time with a sober parent, but it also includes the insecurity of never knowing when the next relapse will occur. Our informants found this instability very demanding, and it made them worry a lot, including worries of the parent's death. This underpins former research on the complexity of the relationships between children and parents with SUD and the need for professional support to cope with it (Alexanderson \& Näsman, 2017; Bath, 2015; Forrester et al., 2016; Kiraly \& Humphreys, 2016; McWey \& Mullis, 2004; Wilson et al., 2012).

\section{A double challenge for professionals}

Recent research emphasizes the need for professionals to help children of parents with SUD to cope during childhood, in order to cope as adults (Bath, 2015; Reupert \& Maybery, 2014; Werner \& Malterud, 2016a; Werner \& Malterud, 2016b). Children want confident professionals who listen, explain and give advice (Freake et al., 2007). Several of our informants lacked professional support during childhood. They were, however, not aware of this need until they became older and arranged therapy for themselves. They struggled a lot on their own with their demanding emotions, to make sense of their situation and to regulate contact with their parents. A better understanding of children who are trapped in 
mixed and contradictory emotions and strong family ties reveals that they should receive support both to deal with their emotions and new family situation and to regulate contact with their parents (Backett-Milburn et al., 2008; Holmila et al., 2011). The informants had several examples of how they tried both to keep distance and to spend time with their parents. Professional support in families who do not live together could contribute to making contact between children and parents safe and confident and may prevent children's experience of loneliness and insecurity (Bullen et al., 2017; Taplin \& Mattick, 2014).

Despite this knowledge, there seems to be a lack of understanding of the necessity of including the whole family when parents suffer from SUD (Alexanderson \& Näsman, 2017; Gullbrå et al., 2016; Selbekk \& Sagvaag, 2016). Parents with SUD often receive welfare support or treatment, but family members do not get the same attention. Looking back on their childhood, some of the informants found it notable that they received no attention and support from their parents' therapists. Child protection services did, of course, focus on the children, but they offered little attention to the relationship between children and parents or to the family as a whole. Professionals may think that, as long as children are physically safe and no longer exposed to substance use, relational support is no longer necessary. Our informants stated the opposite.

Social workers and therapists are affected by sociocultural discourses on parental ideals and expectations in the same way as other people. This may make it challenging to work in families that do not live up to these cultural ideals of parenthood (Smart, 2007; Wilson et al., 2012). In addition, they might be overwhelmed by the complexity of dealing with persons with SUD. The challenge of helping and supporting families were the parents fail in parenting due to SUD could, therefore, prevent them from supporting and treating parents and children as a whole family. As our informants pointed out that this lack of professional attention in childhood had great impact on their coping as adults. This is consistent with other research on adult children of parents with SUD who experience demanding periods and situations as adults due to their childhood (O'Connor et al., 2014; Werner \& Malterud, 2016a; Wiig et al., 2014). Interdisciplinary support in these families, with professionals who 
receive supervision in dealing with this double challenge of inadequate parenting due to SUD, could contribute to making these families more visible.

\section{Methodological reflections}

The study aimed to include informants with different backgrounds. The sample included young people aged 13 to 26 years. There are also differences in how 13-year-olds perceive and reflect on growing up with a parent with SUD compared to those in their mid-twenties. The older ones who lived by themselves mostly described their childhood retrospectively, even though they also talked about their present relationship and contact with the parents. The younger ones, who still lived together with parents or foster parents, mostly talked about the present situation and about the past. While doing in-depth interviews with people in these age groups, we must be aware of the significant emotional and cognitive developments of the brain (Vink et al., 2014). During adolescence and early adulthood, people gradually process and construct their memories and narratives differently and in more advanced ways (Yurgelun-Todd, 2007). Such knowledge has been important and necessary to take into account during the interviews and analysis. That way, including such a broad age span and discussing differences and similarities between age groups made the study more complete. Doing in-depth interviews about sensitive subjects required great awareness, sensitivity and respect for the informant's emotions and boundaries. Due to this, some possible relevant follow-up questions were not asked (Christensen \& James, 2008; Farrell, 2007; Heath, 2009).

\section{Conclusions}

The parents with SUD influenced their children's lives to a large extent, both while they were living together with them and when separated. Therefore, children and young people should be offered sufficient professional support in order to cope with their mixed and contradictory emotions. They are also in need of help to determine the regularity and type of contact with their parents. This could contribute to their coping both during childhood 
and as adults. Professionals should keep the whole family in mind in order to support the children.

\section{References}

Alexanderson, K. \& Näsman, E. (2017) Children's experiences of the role of the other parent when one parent has addiction problems. Drugs: Education, Prevention and Policy, 24, 32-39.

Backett-Milburn, K., Wilson, S., Bancroft, A. \& Cunningham-Burley, S. (2008) Challenging childhoods: Young people's accounts of 'getting by' in families with substance use problems. Childhood, 15, 461479.

Baker, A.J.L., Mehta, N. \& Chong, J. (2013) Foster Children Caught in Loyalty Conflicts: Implications for Mental Health Treatment Providers. The American Journal of Family Therapy, 41, 363-375.

Bath, H. (2015) The Three Pillars of TraumaWise Care: Healing in the Other 23 Hours1. Reclaiming Children and Youth, 23, 5-11.

Bullen, T., Taplin, S., McArthur, M., Humphreys, C. \& Kertesz, M. (2017) Interventions to improve supervised contact visits between children in out of home care and their parents: a systematic review. Child \& Family Social Work, 22, 822-833.

Camí, J. \& Farré, M. (2003) Drug Addiction. The New England Journal of Medicine, 349, 975-986.

Christensen, P. \& James, A. (2008) Research with children : perspectives and practices. Routledge, New York.

Daley, D.C. \& Douaihy, A.B. (2015) Relapse prevention counseling : clinical strategies to guide addiction recovery and reduce relapse : tools for individual or group setting, treatment models $\&$ therapies, group sessions for substance use \& co-occuring disorders. PESI Publishing \& Media.

Dube, S.R., Anda, R.F., Felitti, V.J., Croft, J.B., Edwards, V.J. \& Giles, W.H. (2001) Growing up with Parental Alcohol Abuse: Exposure to Childhood Abuse, Neglect, and Household Dysfunction. Child Abuse \& Neglect: The International Journal, 25, 1627-1640.

Farrell, A. (2007) Ethical Research with Children. McGraw-Hill Education, Maidenhead.

Forrester, D., Holland, S., Williams, A. \& Copello, A. (2016) Helping families where parents misuse drugs or alcohol? A mixed methods comparative evaluation of an intensive family preservation service. Child \& Family Social Work, 21, 65-75.

Freake, H., Barley, V. \& Kent, G. (2007) Adolescents' views of helping professionals: A review of the literature. Journal of Adolescence, 30, 639-653.

Gullbrå, F., Smith-Sivertsen, T., Rortveit, G., Anderssen, N. \& Hafting, M. (2016) III and substanceabusing parents: how can the general practitioner help their children? A qualitative study. BMC family practice, 17, 154.

Haight, W.L., Kagle, J.D. \& Black, J.E. (2003) Understanding and Supporting Parent-Child Relationships during Foster Care Visits: Attachment Theory and Research. Social Work, 48, 195-207.

Halsa, A. (2017) Trapped between madness and motherhood: Mothering alone. Social Work in Mental Health, 1-16.

Heath, B., Cleaver \& Ireland. (2009) Researching Young People's Lives. Sage.

Henden, E. (2016) Addiction, Voluntary Choice, and Informed Consent: A Reply to Uusitalo and Broers. Bioethics, 30, 293-298.

Holmila, M.J., Itääpuisto, M. \& Ilva, M. (2011) Invisible victims or competent agents: Opinions and ways of coping among children aged 12--18 years with problem drinking parents. Drugs: Education, Prevention \& Policy, 18, 179-186.

Järvinen, M. (2015) Understanding Addiction. Journal of Family Issues, 36, 805-825. 
Kallander, E.K., Weimand, B.M., Becker, S., Van Roy, B., Hanssen-Bauer, K., Stavnes, K., Faugli, A., Kufås, E. \& Ruud, T. (2017) Children with ill parents: extent and nature of caring activities. Scandinavian Journal of Caring Sciences.

Kiraly, M. \& Humphreys, C. (2013) Perspectives From Young People about Family Contact in Kinship Care: "Don't Push Us-Listen More". Australian Social Work, 66, 314-327.

Kiraly, M. \& Humphreys, C. (2016) 'It's about the whole family': family contact for children in kinship care. Child \& Family Social Work, 21, 228-239.

Lundby, G. (2014) Creating Different Versions of Life: Talking About Problems with Children and their Parents. Australian and New Zealand Journal of Family Therapy, 35, 31-45.

McWey, L.M., Acock, A. \& Porter, B.E. (2010) The impact of continued contact with biological parents upon the mental health of children in foster care. Children and Youth Services Review, 32, 1338-1345. McWey, L.M. \& Mullis, A.K. (2004) Improving the Lives of Children in Foster Care: The Impact of Supervised Visitation. Family Relations, 53, 293-300.

Moore, Tim, McArthur, Morag \& Noble-Carr, D. (2011) Different but the Same? Exploring the Experiences of Young People Caring for a Parent with an Alcohol or Other Drug Issue. Journal of Youth Studies, 14, 161-177.

Nordfjærn, T. (2011) Relapse patterns among patients with substance use disorders. Journal of Substance Use, 16, 313-329.

O'Connor, L., Forrester, D., Holland, S. \& Williams, A. (2014) Perspectives on children's experiences in families with parental substance misuse and child protection interventions. Children \& Youth Services Review, 38, 66-74.

Raitasalo, K. \& Holmila, M. (2017) Parental substance abuse and risks to children's safety, health and psychological development. Drugs: Education, Prevention and Policy, 24, 17-22.

Reupert, A., Goodyear, M. \& Maybery, D. (2012) Engaging with, and understanding children whose parents have a dual diagnosis. Child \& Adolescent Mental Health, 17, 153-160.

Reupert, A. \& Maybery, D. (2014) Practitioners' experiences of working with families with complex needs. Journal of Psychiatric and Mental Health Nursing, 21, 642-651.

Reupert, A.E. \& Maybery, D. (2010) "Knowledge is Power": Educating Children About Their Parent's Mental Illness. Social Work in Health Care, 49, 630-646.

Selbekk, A.S. \& Sagvaag, H. (2016) Troubled families and individualised solutions: an institutional discourse analysis of alcohol and drug treatment practices involving affected others. Sociology of Health \& IIIness, 38, 1058-1073.

Sellman, D. (2010) The 10 most important things known about addiction. Addiction, 105, 6-13.

Silverman, D. (2006) Interpreting qualitative data : methods for analyzing talk, text and interaction. SAGE, Los Angeles.

Sinclair, I., Wilson, K. \& Gibbs, I. (2001) 'A Life More Ordinary': What Children Want from Foster Placements. Adoption \& Fostering, 25, 17-26.

Smart, C. (2007) Personal life : new directions in sociological thinking. Polity, Cambridge.

Smith, J.A., Larkin, M. \& Flowers, P. (2009) Interpretative phenomenological analysis : theory, method and research. SAGE, Los Angeles.

Söderström, K. \& Skårderud, F. (2013) THE GOOD, THE BAD, AND THE INVISIBLE FATHER: A PHENOMENOLOGICAL STUDY OF FATHERHOOD IN MEN WITH SUBSTANCE USE DISORDER. Fathering, 11, 31-51.

Taplin, S. \& Mattick, R.P. (2014) Supervised contact visits: Results from a study of women in drug treatment with children in care. Children and Youth Services Review, 39, 65.

Templeton, L., Novak, C. \& Wall, S. (2011) Young people's views on services to help them deal with parental substance misuse. Drugs: Education, Prevention and Policy, 18, 172-178.

United Nations. (1989) United Nation General Assembly, Convention on the rights of the child. (ed U. Nations).

Velleman, R., Templeton, L., Reuber, D., Klein, M. \& Moesgen, D. (2008) Domestic abuse experienced by young people living in families with alcohol problems: results from a cross-european study. Child Abuse Review, 17, 387-409. 
Velleman, R. \& Templeton, L.J. (2016) Impact of parents' substance misuse on children: an update. BJPsych Advances, 22, 108-117.

Vink, M., Derks, J.M., Hoogendam, J.M., Hillegers, M. \& Kahn, R.S. (2014) Functional differences in emotion processing during adolescence and early adulthood. Neurolmage, 91, 70.

Werner, A. \& Malterud, K. (2016a) Children of parents with alcohol problems performing normality: A qualitative interview study about unmet needs for professional support. International Journal of Qualitative Studies on Health and Well-being, 11, 30673.

Werner, A. \& Malterud, K. (2016b) Encounters with service professionals experienced by children from families with alcohol problems: A qualitative interview study. Scand J Public Health, 1-8.

Werner, A. \& Malterud, K. (2016c) How can professionals carry out recognition towards children of parents with alcohol problems? A qualitative interview study. Scandinavian journal of public health.

Wiig, E.M., Haugland, B.S.M., Halsa, A. \& Myhra, S.M. (2014) Substance-dependent women becoming mothers: breaking the cycle of adverse childhood experiences. Child \& Family Social Work, n/a-n/a.

Wilson, S., Cunningham-Burley, S., Bancroft, A. \& Backett-Milburn, K. (2012) The consequences of love: young people and family practices in difficult circumstances. Sociological Review, 60, 110-128.

Yurgelun-Todd, D. (2007) Emotional and cognitive changes during adolescence. Current opinion in neurobiology, 17, 251.

How to cite this article: Wangensteen T, Bramness JG, Halsa A. Growing up with parental substance use disorder: The struggle with complex emotions, regulation of contact, and lack of professional support. Child \& Family Social Work. 2018;1-8. https://doi.org/10.1111/cfs.12603 